\title{
Effect of Co-combustion Ratio on the Combustion Characteristics in the LNG/diesel Dual-fuel Engine
}

\author{
Jun Xie ${ }^{1, a^{*}}$, Chunhua Zhang ${ }^{1, b}$, Gang $\mathrm{Li}^{1, \mathrm{c}}$, Juxiang Fang ${ }^{1, \mathrm{~d}}$ \\ ${ }^{1}$ School of Automobile, Chang'an University, Xi'an 710064,

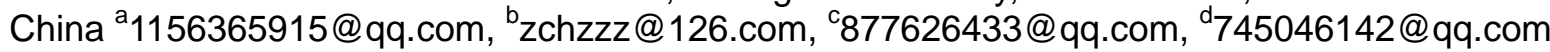

Keyword: LNG/diesel dual-fuel; combustion characteristics; co-combustion ratio

\begin{abstract}
To investigate the effect of co-combustion ratio (CCR) on the combustion characteristics in the LNG/diesel dual-fuel engine, an electronically controlled common rail diesel engine is modified into an LNG/diesel dual-fuel engine by adding a set of LNG supply system and dual-fuel control system. The in-cylinder pressure, pressure rise rate (PPR) and heat release rate (HRR) are compared and analyzed under the conditions of different CCR at engine speed of $1400 \mathrm{r} / \mathrm{min}$, engine load rate of $60 \%$. The results show that the in-cylinder pressure, PRR and HRR of dual-fuel mode are higher than those of original mode and increase as the CCR increases.
\end{abstract}

\section{Introduction}

The energy shortage and environment pollution have been a global problem, of which the diesel engine account for a great percent. Diesel engine is widely used all over the world, especially in Europe, all trucks, buses and about $34 \%$ of cars are equipped with diesel engines. So it is important to improve the diesel engine thermal efficiency and decrease the soot pollution. To find an alternative clean fuel is a proper way to solve the problem [1]. LNG is a competent fuel for its physical and chemical properties.

The dual-fuel combustion is a new combustion mode which can be applied on diesel engine. In the experiment, NG and air are mixed in the mixer to form homogeneous mixture [2]. When the piston reaches the compression top dead center, diesel is directly injected into the cylinder as ignition source to ignite the NG-air premixed mixture to achieve the dual-fuel combustion. Due to the LNG-air premixed mixture combustion, the LNG/diesel dual-fuel engine has high thermal efficiency and less soot emission. The combustion performance of dual-fuel engine is varied with the different quantity of LNG and diesel [3]. CCR is defined as the percentage of the total energy that the NG energy accounts for. The experiment investigates the effect of CCR on the combustion characteristics of LNG/diesel dual-fuel engine in several parts, including the in-cylinder pressure, PRR and HRR.

\section{Experiment apparatus}

The electronically controlled common rail diesel engine is modified to a LNG/diesel dual-fuel engine by adding a set of LNG supply system and dual-fuel control system. The specifications of the diesel engine are listed in Table 1.

Table 1 The specifications of test engine

\begin{tabular}{cc}
\hline Items & Values \\
\hline Model & YC6G270-30 \\
Bore $(\mathrm{mm}) \times$ stroke $(\mathrm{mm})$ & $112 \times 132$ \\
Compression ratio & $17.5: 1$ \\
Displacement $(\mathrm{L})$ & 7.8 \\
Rated power/engine speed $(\mathrm{kW} / \mathrm{r} / \mathrm{min})$ & $199 / 2200$ \\
Rated torque/engine speed $(\mathrm{N} \cdot \mathrm{m} / \mathrm{r} / \mathrm{min})$ & $1080 / 1400 \sim 1600$ \\
\hline
\end{tabular}

The schematic diagram of experimental apparatus is showed as Fig.1. The LNG supply system consists of LNG tank, LNG vaporizer, pressure regulator, LNG buffer tank, electromagnetic safety 
valve, NG flow meter and NG injection valve. The NG injection pressure is fixed at $0.8 \mathrm{MPa}$, and its consumption is measured by the NG flow meter (Shaanxi Aeospace Power HLQZ-Z-60). Diesel consumption is measured by the diesel fuel meter (Gregory FCS3). The in-cylinder pressure is collected by the piezo-electric cylinder pressure sensor (6052A, Kistler), and the pressure signal is amplified by the electric charge amplifier (5019, Kistler). The PRR and HRR are calculated by the in-cylinder pressure.

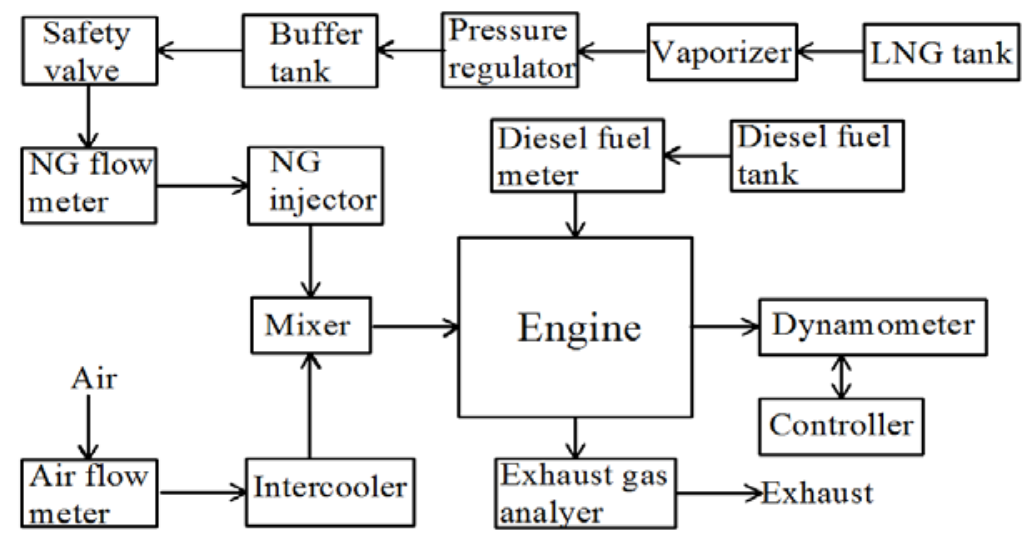

Fig.1 Schematic diagram of experimental system

The LNG/diesel dual-fuel electronically controlled system mainly includes diesel engine ECU, analog load cell, dual-fuel ECU, state control box and a variety of sensors. According to the engine working conditions, the system can automatically switch mode within four working modes, including diesel mode, follow-up mode, bypass mode and dual-fuel mode. However, under the conditions, such as LNG nozzle circuit failure, sensor failure and dual-fuel system failure, the engine control system will automatically switch back to the original mode.

\section{Experiment procedure}

CCR is defined as the percentage of the total energy that the NG energy accounts for, it can be calculated by the following formula.

$$
C C R=\frac{m_{L N G} \times H_{u_{L N G}}}{m_{L N G} \times H_{u_{L N G}}+m_{\text {diesel }} \times H_{u_{\text {diesel }}}}
$$

Where $m_{L N G}$ is the consumption of LNG $(\mathrm{kg} / \mathrm{h}), m_{\text {diesel }}$ is the consumption of diesel $(\mathrm{kg} / \mathrm{h}), H_{u_{L N G}}$ is the low heat value of LNG, $H_{u_{\text {diesel }}}$ is the low heat value of diesel. CCR $=0 \%$ represents diesel mode and CCR $>0 \%$ represents dual-fuel mode [4].

Experiment was performed at a constant speed of $1400 \mathrm{r} / \mathrm{min}$ and load rate of $60 \%$. Firstly the engine was supplied with diesel only. The values of power, torque, throttle position, fuel rail pressure, coolant temperature, fuel consumption were recorded when the engine speed and coolant temperature were in stable state. Under the same throttle position, the engine was switched to LNG / diesel dual-fuel mode by increasing NG injection quantity and decreasing diesel injection quantity. Calibration software was utilized to keep the same engine speed and load rate with those of the original mode. Then the relative parameters values were recorded as above. Besides, in order to make the measured values more accurate, the engine was allowed to run for a few minutes until it was in steady running state before each measurement.

\section{Results and discussion}

In-cylinder pressure. Fig. 2 shows the in-cylinder pressure traces under different CCR. As it shows that dual-fuel mode in-cylinder pressure is higher than the original mode. With the increase of CCR, the dual-fuel mode in-cylinder pressure increases. 


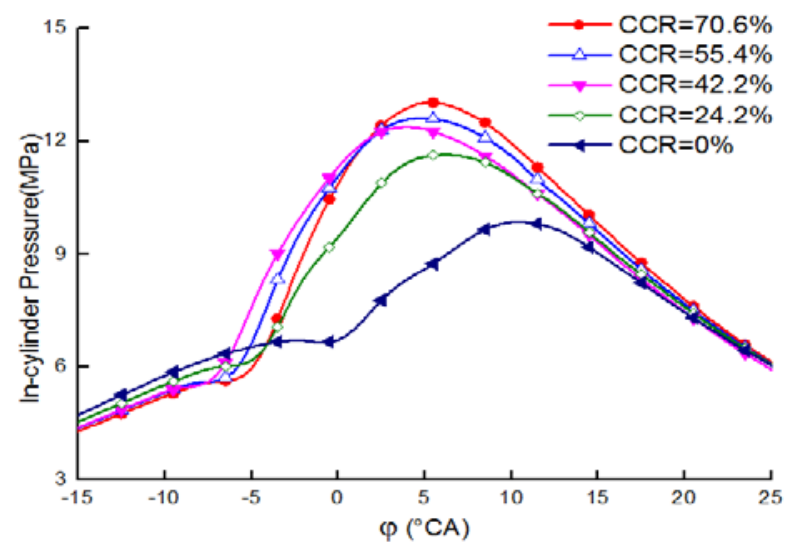

Fig.2 The in-cylinder pressure under different CCR

Except for the diesel diffusion combustion, the dual-fuel mode also consists of NG port injection, which leads to a longer ignition delay period to form more premixed homogeneous mixture. As a result, combustion rate is accelerated to achieve higher in-cylinder pressure. With the increase of CCR, the concentration of NG-air mixture thickens, which accelerates the combustion rate, and increases the in-cylinder pressure; In addition, ignition delay period becomes longer and forms more combustible mixture further to enhance combustion pressure.

Pressure rise rate (PRR). Fig. 3 shows the in-cylinder pressure rise rate traces under different CCR. As can be seen, compared with the original mode, dual-fuel mode PRR increases, due to the NG-air premixed homogeneous mixture has a faster combustion rate. As it shows with the increase of CCR, dual-fuel mode PRR increases. It can be explained that NG-air mixture concentration increases as the CCR increases, and because of multi-point simultaneous ignition, combustion rate increases, PRR increases. Besides, with the increase of CCR, dual-fuel ignition delay period becomes longer, more combustible mixture is formed to lead higher PRR.

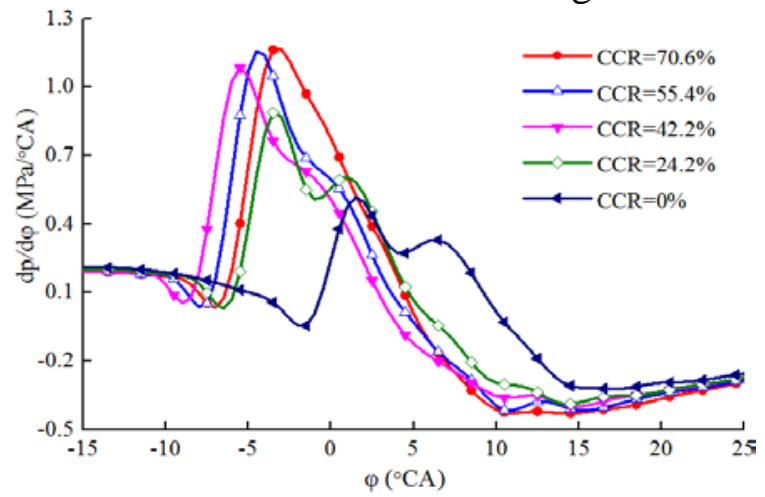

Fig.3 Pressure rise rate under different CCR

Heat release rate (HRR). Fig. 4 shows the heat release rate traces under different CCR. As can be seen, compared with the original mode, the heat release rate of dual-fuel mode is increased. As the CCR increases, the heat release rate of dual-fuel mode increases.

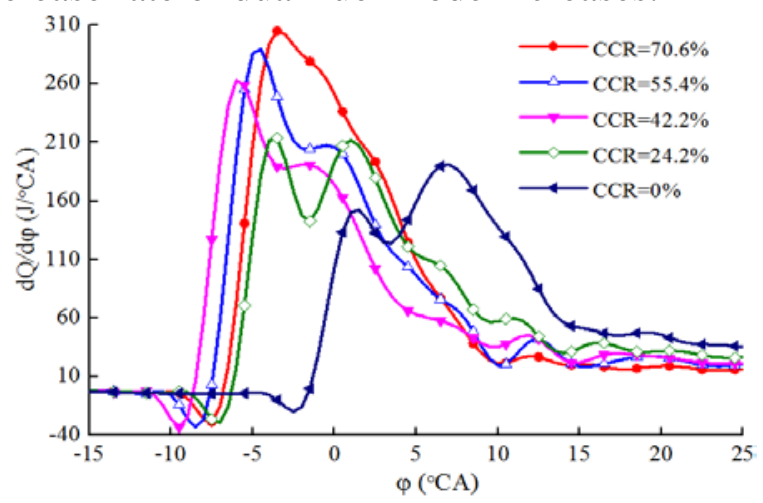

Fig.4 Heat release rate under different CCR

The original mode and $\mathrm{CCR}=24.2 \%$ dual-fuel mode have two obvious peaks. Because the original mode is diesel double injection, the first peak is stand for the pre-injection diesel 
combustion and the second peak is stand for the main injection diesel combustion. For the dual-fuel mode, the first peak is stand for the NG-air mixture and less diesel-air mixture combustion, the second peak is stand for the diesel diffusion combustion. When the CCR $=24.2 \%$, the NG-air mixture has low concentration, diesel diffusion combustion is the main combustion, so the second peak is still obvious. With the increase of CCR, NG-air mixture has high concentration, and the diesel decreases, so the second peak becomes small until disappears.

With the increase of CCR, NG-air mixture concentration increases, because of multi-point simultaneous ignition, combustion rate increases, so the heat release rate increases. In addition, compared with diesel, NG and air is more likely to occur reaction before the flame, NG-air homogeneous mixture has higher combustion rate and improves the heat release rate.

\section{Conclusion}

(1) Dual fuel mode in-cylinder pressure is higher than the original model. As the CCR increases, the dual-fuel mode in-cylinder pressure increases.

(2) Dual fuel mode in-cylinder pressure rise rate is higher than the original model. As the CCR increases, the dual-fuel mode in-cylinder pressure increases.

(3) Dual fuel mode heat release rate is obviously higher than the original model. As the CCR increases, the dual-fuel mode heat release rate increases.

\section{Reference}

[1]. Lei Liu, Fuyuan Yang, Minggao Ou. Control and optimization of diesel/LNG system of a 4G200 diesel engine. Journal of Jilin University (Engineering and Technology Edition). Vol. 45 (2015), P.2-5

[2]. Lianchao Duan: Investigation of combustion cyclic variation from a LNG/Diesel dual fuel engine. (Master, Jilin University, 2015).p.27-38

[3]. Jiantong Song, Chunhua Zhang, Han Wu, Jinzhu Chen. Effects of replace ratio on engine fueled with natural gas with a pilot diesel fuel. Journal of Gansu Agricultural University. Vol. 47 (2012), p.151

[4]. Qiang shi, Chunhua Zhang, Yanchao Cai. Effects of load ratio on dual-fuel engine operated with pilot diesel fuel and liquefied natural gas. Advanced Materials Research. Vols. 960-961 (2014). P.3-5 